\title{
SISTEM PAKAR PENDIAGNOSA PENYAKIT TUBERKULOSIS
}

\author{
Nur Aini ${ }^{1)}$, Ramadiani ${ }^{2)}$, Heliza Rahmania Hatta ${ }^{3)}$ \\ 1,2,3) Ilmu Komputer, Fakultas Ilmu Komputer dan Teknologi Informasi, Universitas Mulawarman \\ Jl.K.H Wahid Hasyim II, Samarinda, 75119 \\ E-Mail : nurshafaafi@gmail.com ${ }^{1)}$,mmi_ugm04@yahoo.com ${ }^{2)}$, heliza.rahmania@gmail.com ${ }^{3)}$
}

\begin{abstract}
ABSTRAK
Tuberkulosis merupakan penyakit infeksi yang mudah menular melalui udara yang disebabkan oleh kuman Mycobacterium Tuberculosis. Tuberkulosis sebagian besar menyerang paru namun penyakit ini juga menyerang organ tubuh lain yang disebut ekstra paru. Kurangnya fasilitas dan pengetahuan masyarakat dapat memperlambat diagnosa awal Tuberkulosis Ekstra Paru sehingga dapat membahayakan keselamatan masyarakat. Maka diperlukannya sistem pakar yang berguna untuk mendiagnosa penyakit Tuberkulosis yang dapat mempermudah penderita dalam melakukan diagnosa awal penyakit Tuberkulosis agar segera mendapatkan penanganan yang tepat. Tujuan dari penelitian ini adalah membangun sistem pakar pendiagnosa penyakit Tuberkulosis dengan menggunakan metode Certainty Factor. Aplikasi ini akan mendiagnosa penyakit dengan melakukan penelusuran gejala-gejala yang ada berdasarkan inferensi forward chaining. Penelitian ini menghasilkan sebuah sistem pakar berbasis web dengan tingkat akurasi sebesar $85 \%$ yang dimanfaatkan untuk membantu tenaga kesehatan dan masyarakat umum dalam mendiagnosa awal penyakit Tuberkulosis.
\end{abstract}

Kata Kunci : Tuberkulosis, Sistem Pakar, Certainty Factor, Forward Chaining

\section{PENDAHULUAN}

Tuberkulosis (TB) merupakan penyakit menular langsung yang disebabkan oleh infeksi bakteri Mycobacterium tuberculosis. TB merupakan penyakit yang mudah menular melalui udara dari sumber penularan yaitu pasien TB BTA positif pada waktu batuk atau bersin, pasien menyebarkan kuman ke udara dalam bentuk percikan dahak. Sekali batuk dapat menghasilkan sekitar 3000 percikan dahak [7].

TB dapat menyerang siapa saja, terutama usia produktif/masih aktif bekerja dan anak-anak. Sekitar 75\% pasien TB adalah kelompok usia yang paling produktif secara ekonomis (15-50 tahun). Diperkirakan seorang pasien TB dewasa akan kehilangan rata-rata waktu kerjanya 3 sampai 4 bulan. Jika ia meninggal akibat TB, maka akan kehilangan pendapatannya sekitar 15 tahun. Selain merugikan secara ekonomis, TB juga memberikan dampak buruk lainnya secara sosial bahkan dikucilkan oleh masyarakat [3].

Indonesia berkontribusi sebesar 5,8\% dari kasus TB yang ada di dunia. TB merupakan masalah utama kesehatan masyarakat dan menjadi tantangan dalam masalah kesehatan masyarakat di Indonesia dengan masih adanya sekitar 430.000 pasien baru per tahun dan angka insiden 189/100.000 penduduk serta angka kematian akibat TB sebesar 61.000 per tahun atau 27/100.000 penduduk [6]. Menurut laporan WHO tahun 2013, Indonesia menempati urutan ketiga jumlah kasus TB setelah India dan Cina dengan jumlah sebesar 700 ribu kasus. Angka kematian masih sama dengan tahun 2011 sebesar 27 per 100.000 penduduk, tetapi angka insidennya turun menjadi 185 per 100.000 penduduk di tahun 2012 [15].

Sebagian besar kuman TB menyerang paru, tetapi dapat juga mengenai organ tubuh lainnya yang biasa disebut dengan TB Ekstra Paru. TB Paru merupakan bentuk yang paling sering dijumpai yaitu sekitar $80 \%$ dari semua penderita. TB yang menyerang jaringan paru-paru ini merupakan satusatunya bentuk dari TB yang mudah menular. TB Ekstra Paru merupakan bentuk penyakit TB yang menyerang organ tubuh lain selain paru-paru. TB pada dasarnya ini tidak pandang bulu karena kuman ini dapat menyerang semua organ dari tubuh [4].

Masyarakat hanya mengetahui bahwa TB menyerang bagian paru saja pada umumnya, namun TB juga dapat menyerang organ lain selain paru yang disebut ekstra paru. TB Ekstra Paru terjadi ketika kuman TB menyebar ke bagian organ tubuh lain melalui aliran darah. Diagnosis pasti untuk penyakit TB sering sulit ditegakkan sedangkan diagnosis kerja dapat ditegakkan berdasarkan gejala klinis TB yang kuat (presumtif) dengan menyingkirkan kemungkinan penyakit lain.

Kurangnya fasilitas yang memadai, dokter ahli yang tidak selalu ada di tempat dan kurangnya pengetahuan pasien mengenai penyakit TB seringkali membuat diagnosis TB terlambat yang bisa mengancam kesehatan pasien. Sebuah aplikasi komputer yang sistematis sebagai alat bantu untuk melakukan diagnosis awal penyakit TB sangat diperlukan untuk memudahkan tenaga ahli dalam menemukan bagian organ tubuh mana yang terserang penyakit TB dan dapat mempercepat hasil diagnosa sehingga tenaga ahli dapat memberikan penanganan yang tepat. 
Sistem yang dibangun dalam penelitian ini adalah sistem yang menggunakan keahlian pakar dalam bidang kesehatan dengan menggunakan metode certainty factor dalam mendiagnosa sebuah penyakit. Menurut Martin dan Oxman (1988), sistem pakar adalah sistem berbasis komputer yang menggunakan pengetahuan, fakta, dan teknik penalaran dalam memecahkan masalah, yang biasanya hanya dapat diselesaikan oleh seorang pakar dalam bidang tertentu. Menurut Sari (2013), metode Certainty Factor merupakan metode yang mendefenisikan ukuran kepastian terhadap fakta atau aturan, untuk menggambarkan tingkat keyakinan pakar terhadap masalah yang sedang dihadapi, dengan menggunakan Certainty Factor dapat menggambarkan tingkat keyakinan pakar terhadap suatu penyakit.

Terdapat penelitian "Sistem Pakar untuk Mendiagnosa Penyakit Polip Nasi (Polip Hidung) Menggunakan metode Certainty Factor”. Hasil dari penelitian ini adalah memberikan keputusan yang cukup akurat mengenai diagnosa penyakit polip nasi berdasarkan penerapan metode Certainty Factor yang digunakan [1].

Berdasarkan latar belakang diatas, penulis membangun Sistem Pakar Pendiagnosa Penyakit Tuberkulosis Menggunakan Metode Certainty Factor yang mampu memberikan diagnosis akan kemungkinan seorang pasien menderita penyakit TB beserta cara pengobatannya.

\section{TINJAUAN PUSTAKA}

\section{a. Sistem Pakar}

Sistem pakar (expert system) merupakan paket perangkat lunak atau paket program komputer yang ditujukan sebagai penyedia nasihat dan sarana bantu dalam memecahkan masalah dalam bidangbidang spesialisasi tertentu seperti sains, perekayasaan matematika, kedokteran, pendidikan dan sebagainya [14].

\section{b. Struktur Sistem Pakar}

Sistem pakar disusun oleh dua bagian utama, yaitu lingkungan pengembangan dan lingkungan konsultasi. Lingkungan pengembangan digunakan untuk memasukkan pengembangan pakar ke dalam lingkungan sistem pakar. Lingkungan konsultasi digunakan oleh nonpakar untuk memperoleh pengetahuan dan nasihat pakar. Kebanyakan sistem pakar saat ini tidak berisi komponen perbaikanpengetahuan [14].

\section{c. Mesin Inferensi}

Mesin inferensi adalah program komputer yang memberikan metodologi untuk penalaran tentang informasi yang ada dalam basis pengetahuan dan dalam workplace untuk memformulasikan kesimpulan [2]. Penelitian menggunakan runut maju (Forward Chaining). Runut maju berarti menggunakan himpunan kondisi-aksi. Dalam metode ini, data digunakan untuk menentukan aturan mana yang dijalankan kemudian aturan tersebut dijalankan, proses diulang sampai ditemukan suatu hasil. Menurut Giarrattano dan Riley, metode inferensi runut maju cocok digunakan untuk menangani masalah pengendalian (controlling) dan peramalan (prognosis) [8].

\section{d. Tubekulosis}

Tuberkulosis (TB) adalah suatu infeksi menular dan bisa berakibat fatal disebabkan oleh Mycobacterium tuberculosis, Mycobacterium bovis atau Mycobacterium africanum. TB menunjukkan penyakit yang paling sering disebabkan oleh Mycobacterium tuberculosis, tetapi kadang disebabkan oleh Mycobacterium bovis atau Mycobacterium africanum. Di negara berkembang, anak-anak terinfeksi oleh mikobakterium lainnya yang menyebabkan TB. Organisme ini disebut Mycobacterium bovis, yang bisa disebarkan melalui susu yang tidak disterilkan [10].

Penyakit TB merupakan penyakit kronis atau menahun yang telah lama dikenal oleh masyarakat luas. Penemuan Robbert Kock pada tahun 1882 secara meyakinkan telah dapat memberikan bukti bahwa tuberkulosis adalah suatu penyakit infeksi yang disebabkan oleh bakteri yang diberi nama Mycobacterium tuberculosis. Orang yang pertama kali dapat membuktikan bahwa TB adalah suatu penyakit yang dapat ditularkan yaitu Villenim yang hidup pada tahun 1827-1894. Penyakit TB biasa terdapat pada paru-paru, tetapi mungkin juga pada organ lain seperti kelenjar getah bening (nodus lymphaticus) [11].

\section{e. Gejala Penyakit Tuberkulosis}

Beberapa Penyakit TB yang sering diderita oleh masyarakat adalah:

1. Tuberkulosis Paru

TB Paru adalah penyakit radang parenkim paru yang disebabkan oleh infeksi kuman Mycobacterium Tuberculosis. TB Paru mencakup $80 \%$ dari keseluruhan kejadian penyakit TB sedangkan 20\% selebihnya merupakan TB Ekstra Paru.

a. Gejala utama

Batuk terus-menerus dan berdahak selama tiga minggu/lebih.

b. Gejala tambahan yang sering dijumpai

1) Dahak bercampur darah/batuk darah.

2) Demam selama tiga minggu atau lebih

3) Sesak nafas dan nyeri dada.

4) Penurunan nafsu makan.

5) Berat badan turun.

6) Rasa kurang enak badan (malaise, lemah.

7) Berkeringat di malam hari walaupun tidak melakukan apa-apa

2. TB Ekstra Paru

TB Ekstra Paru merupakan penyakit yang disebabkan oleh infeksi kuman Mycobacterium 
Tuberculosis yang menyerang organ tubuh selain paru. Penyakit ini biasanya terjadi karena kuman menyebar dari bagian paru ke bagian organ tubuh lain melalui aliran darah.

a. Tuberkulosis Kelenjar Getah Bening

TB Kelenjar atau Limfadenitis Tuberculosis adalah penyakit radang kelenjar getah bening yang disebabkan oleh infeksi kuman Mycobacterium Tuberculosis. Kelenjar getah bening yang biasa diserang adalah bagian leher, ketiak, dan sela paha.

1) Gejala sistemik/umum:

a) Batuk terus-menerus dan berdahak selama tiga minggu/lebih

b) Demam selama tiga minggu/lebih

c) Penurunan nafsu makan

d) Berat badan turun

e) Rasa kurang enak badan/malaise, lemah

f) Berkeringat di malam hari walaupun tidak melakukan apa-apa

2) Gejala Khusus

a) Munculnya benjolan-benjolan pada bagian yang mengalami gangguan kelenjar seperti leher, sela paha, serta ketiak.

b) Ada tanda-tanda radang di daerah sekitar benjolan kelenjar.

c) Benjolan kelenjar mudah digerakkan.

d) Benjolan kelenjar yang timbul terasa kenyal.

e) Membesarnya benjolan kelenjar yang mengakibatkan hari demi hari kondisinya semakin memburuk dan merusak tubuh.

f) Benjolan kelenjar pecah dan mengeluarkan cairan seperti nanah kotor.

g) Terdapat luka pada jaringan kulit atau kulit yang disebabkan pecahnya benjolan kelenjar getah bening.

b. Tuberkulosis Payudara

TB Payudara adalah penyakit radang payudara yang disebabkan oleh infeksi kuman Mycobacterium Tuberculosis.

1) Gejala sistemik/umum:

a) Batuk terus-menerus dan berdahak selama tiga minggu/lebih.

b) Demam selama tiga minggu/lebih

c) Penurunan nafsu makan.

d) Berat badan turun.

e) Rasa kurang enak badan (malaise), lemah.

f) Berkeringat di malam hari walaupun tidak melakukan apa-apa.

2) Gejala Khusus

a) Timbulnya benjolan di payudara.

b) Rasa nyeri di bagian payudara.

c) Adanya tanda radang di sekitar benjolan yang timbul di payudara. c. TB Tulang Belakang (Spondilitis)

TB Tulang Belakang atau Spondilitis Tuberculosis adalah penyakit radang tulang belakang yang disebabkan oleh infeksi kuman Mycobacterium Tuberculosis.

1) Gejala sistemik/umum:

a) Batuk terus-menerus dan berdahak selama tiga minggu/lebih.

b) Demam selama tiga minggu/lebih

c) Penurunan nafsu makan

d) Berat badan turun

e) Rasa kurang enak badan/malaise, lemah

f) Berkeringat di malam hari walaupun tidak melakukan apa-apa

2) Gejala Khusus

a) Rasa nyeri pada bagian punggung atau mengalami kekakuan punggung.

b) Penderita enggan menggerakkan punggungnya.

c) Penderita menolak untuk membungkuk atau mengangkat barang dari lantai, bila diminta penderita akan menekuk lututunya agar punggung tetap lurus.

d) Rasa nyeri pada punggung berkurang bila penderita beristirahat.

e) Timbulnya benjolan di bagian punggung/tulang belakang.

\section{f. Metode Certainty Factor}

Seorang pakar sering kali menganalisis informasi yang ada dengan ungkapan seperti “mungkin”, "kemungkinan besar”, "hampir pasti”, untuk mengakomodasi hal ini kita menggunakan Certainty Factor (CF) guna menggambarkan tingkat keyakinan pakar terhadap masalah yang sedang terjadi [14]. Faktor Kepastian (Certainty Factor) menyatakan kepercayaan dalam sebuah kejadian (fakta atau hipotesis) berdasarkan bukti atau penilaian pakar [15]. Salah satu cara dalam mendapatkan tingkat keyakinan (CF) dari sebuah rule adalah dengan cara mewawancarai seorang pakar yaitu nilai CF(Rule) didapat dari interpretasi "term” pakar yang diubah menjadi nilai CF tertentu sesuai tabel 1 berikut [14].

Tabel 1. Nilai CF dan Interpretasi

\begin{tabular}{|l|c|}
\hline \multicolumn{1}{|c|}{ Uncertain Term } & CF \\
\hline Definitely not (pasti tidak) & -1.0 \\
\hline Almost certainly not (hampir pasti tidak) & -0.8 \\
\hline Probably not (kemungkinan besar tidak) & -0.6 \\
\hline Maybe not (mungkin tidak) & -0.4 \\
\hline Unknown (tidak tahu) & -02 to 0.2 \\
\hline Maybe (mungkin) & 0.4 \\
\hline Probably (kemungkinan besar) & 0.6 \\
\hline Almost certainly (hampir pasti) & 0.8 \\
\hline Definitely (pasti) & 1.0 \\
\hline
\end{tabular}

(Sumber: T.Sutejo dkk, 2011)

Secara umum, rule direpresentasikan dalam bentuk sebagai berikut [14] : 


\author{
IF $\mathrm{E}_{1}$ AND $\mathrm{E}_{2} \ldots . A N D \mathrm{E}_{\mathrm{n}}$ THEN H (CF rule) \\ Atau \\ IF $\mathrm{E}_{1} \mathrm{OR} \mathrm{E}_{2} \ldots . . \mathrm{OR} \mathrm{E}_{\mathrm{n}}$ THEN H (CF rule)
}

Di mana:

$$
\begin{array}{ll}
\text { IF E } \mathrm{E}_{1 . . . E_{\mathrm{n}}} & \text { : Fakta-fakta (evidence) yang ada } \\
\mathrm{H} & \text { : Hipotesis atau konklusi yang } \\
& \text { dihasilkan } \\
\text { CF Rule } & \text { : Tingkat keyakinan terjadinya } \\
\multicolumn{2}{c}{\text { hipotesis H akibat adanya fakta }}
\end{array}
$$

1. Rule evidence $\mathrm{E}$ tunggal dan hipotesis $\mathrm{H}$ tunggal IF E THEN $\mathrm{H}$ (CF rule) $\mathrm{CF}(\mathrm{H}, \mathrm{E})=\mathrm{CF}(\mathrm{E}) \times(\mathrm{CF}$ rule $)$

2. Rule evidence $\mathrm{E}$ ganda dan hipotesis $\mathrm{H}$ tunggal IF $\mathrm{E}_{1}$ AND $\mathrm{E}_{2} \ldots$...AND $\mathrm{E}_{\mathrm{n}}$ THEN H (CF rule) $\left.\mathrm{CF}\left(\mathrm{E}_{\mathrm{n}}\right)\right] \times \mathrm{CF}($ rule $)$

3. Kombinasi dua buah rule dengan evidence berbeda ( $E_{1}$ dan $\left.E_{2}\right)$, hipotesis sama.

IF $\mathrm{E}_{1}$ THEN $\mathrm{H}$ Rule 1

$\mathrm{CF}\left(\mathrm{H}, \mathrm{E}_{1}\right)=\mathrm{CF}_{1}=\left(\mathrm{E}_{1}\right) \times \mathrm{CF}($ Rule 1$)$

IF E2 THEN H Rule 2

$\mathrm{CF}\left(\mathrm{H}, \mathrm{E}_{2}\right)=\mathrm{CF}_{2}=\mathrm{C}\left(\mathrm{E}_{2}\right) \times \mathrm{CF}($ Rule 2$)$

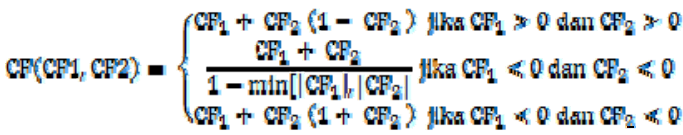

\section{g. Penelitian}

Pemenuhan konsep sistem pakar dengan basis pengetahuan dilakukan dengan pengumpulan data dan informasi terkait jenis penyakit Tuberkulosis Ekstra Paru, dengan studi pustaka dan konsultasi dengan pakar Tuberkulosis. Basis data dilakukan dengan analisis dan perancangan menggunakan Unified Modelling Language (UML). Adapun konsep inference engine dilakukan dengan penggunaan production rule (if..then) mekanismenya melalui forward chaining serta penilaian bobot menggunakan nilai CF dan intrepretasinya. Adapun konsep user interace dan dialog dikembangkan dengan pembuatan antarmuka yang user friendly bagi kemudahan dalam pengisian data dan fakta. Keluaran yang disajikan berupa informasi diagnosa penyakit Tuberkulosis dan nilai kemungkinan penyakit yang didiagnosis menyerang, sedangkan uji validitas hasil diagnosis dikomparasi dengan data pakar.

\section{HASIL DAN PEMBAHASAN}

\section{a. Deskripsi Sistem}

Sistem pakar pendiagnosa penyakit Tuberkulosis Paru dan Ekstra Paru ini tidak digunakan untuk mendiagnosa penyakit Tuberkulosis pada anak-anak yaitu anak berusia 012 tahun. Pendiagnosaan penyakit Tuberkulosis Paru Dan Ekstra Paru pada anak-anak memiliki metode tersendiri yaitu dengan menggunakan metode Scoring. Dengan demikian, pengguna yang dapat berkonsultasi menggunakan sistem pakar ini adalah pengguna yang berusia lebih dari 12 tahun.

Sistem pakar untuk diagnosa penyakit Tuberkulosis ini menggunakan metode inferensi forward chaining (penalaran maju) dan teori faktor kepastian (certainty factor), dalam metode ini user akan memilih gejala sesuai dengan yang dialaminya, kemudian sistem akan mengecek satu demi satu gejala yang dipilih user apakah rule di dalam database ada yang sesuai dengan inputan user. Jika ada maka sistem akan melakukan perhitungan nilai CF sesuai dengan rule yang terpilih. Sistem akan memberikan output berupa nama penyakit, besarnya nilai persentase hasil diagnosis sistem, daftar gejala yang telah dipilih user, serta penjelasan solusi penanganan dan pengobatan penyakit.

User dapat mengisi kuisioner resiko sebelum user memilih gejala sesuai dengan yang dialaminya dengan menjawab pertanyaan umum mengenai resiko kejadian Tuberkulosis untuk mengetahui besarnya resiko user untuk terserang penyakit Tuberkulosis dengan melihat faktor resiko yang ada pada user. Sistem akan mengecek jawaban user tersebut apakah sesuai dengan aturan faktor resiko dan memberikan hasil user tersebut beresiko untuk terserang penyakit atau tidak. Jika user beresiko terserang penyakit maka sistem akan menyarankan user untuk melakukan konsultasi dengan memilih gejala sesuai yang dialaminya, jika tidak beresiko maka sistem akan memberikan kebebasan kepada user untuk tetap lanjut berkonsultasi atau tidak. Sistem juga memberikan informasi penyakit mengenai jenis penyakit Tuberkulosis sehingga sistem ini juga berfungsi layaknya sistem informasi. Data mengenai gejala penyakit dan nilai keyakinannya diperoleh dari seorang pakar yaitu Bapak Eko Haryanto, A.md.Kep dalam hal ini adalah Koordinator Tuberkulosis, Kusta dan Malaria pada Puskesmas Lempake Samarinda untuk mendukung pembuatan sistem pakar ini sehingga sistem dapat bekerja layaknya seorang pakar dan dapat menjadi alternatif pendiagnosaan penyakit yang lebih hemat dan efisien.

\section{b. Faktor Resiko Kejadian Tuberkulosis}

Berdasarkan literatur dan wawancara dengan Pakar Tuberkulosis yaitu Bapak Romi Hendra, S.K.M. bahwa seseorang dikatakan memiliki kemungkinan resiko untuk terserang Tuberkulosis apabila memenuhi faktor resiko paling kurang satu dari faktor berikut:

1) Rumah tempat tinggal tidak tersedia atau tidak memiliki ventilasi

2) Jendela rumah tidak dibuka setiap hari atau tidak memiliki jendela rumah

3) Keadaan rumah pengap dan lembab

4) Sinar matahari yang masuk ke dalam rumah tidak cukup yang ditandai dengan tidak adanya cahaya terang dari sinar matahari pada siang 
hari di dalam rumah

5) Tinggal di lingkungan yang kumuh

6) Minum Alkohol

7) Perokok dan mantan perokok

8) Mengalami gizi buruk atau malnutrisi

9) Menderita HIV/AIDS

10) Menderita Diabetes

11) Tinggal serumah dengan penderita TB Paru

12) Tinggal serumah dengan lebih dari satu penderita TB Paru

13) Adanya kontak dengan penderita TB Paru di luar rumah secara intensif seperti tempat kerja, sekolah, dll.

\section{c. Perancangan Sistem}

Perancangan sistem pakar diagnosa awal penyakit Tuberkulosis yang dikembangkan menggunakan menggunakan diagram unified modeling language (UML), diagram yang digunakan yaitu use case diagram dan activity diagram. Usecase diagram merupakan suatu langkah penting yang harus dilakukan dalam menyelesaikan suatu masalah. Berisi alur untuk membantu bagaimana suatu sistem dapat berjalan. Gambar 1 merupakan usecase diagram sistem pakar diagnosa awal penyakit Tuberkulosis.

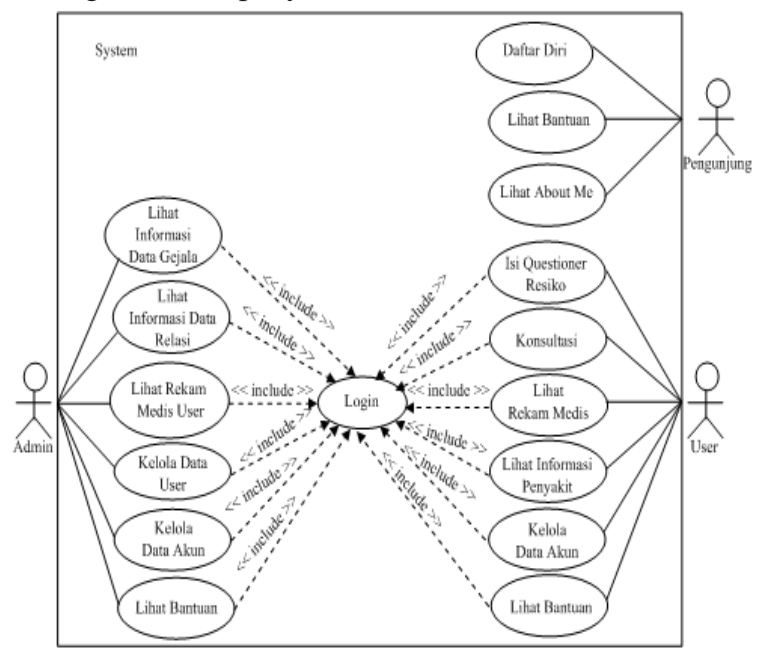

Gambar 1. Usecase Diagram Sistem

\section{d. Perancangan Basisdata}

Fakta dan pengetahuan yang berhubungan dengan gejala-gejala Tuberkulosis Paru dan Ekstra Paru akan digunakan dalam mengambil suatu kesimpulan dalam pembuatan sistem pakar. Fakta dan pengetahuan tersebut didapatkan dari hasil studi literatur dan wawancara. Setiap jenis penyakit Tuberkulosis pasti memiliki gejala-gejala yang dapat diindentifikasi berdasarkan pengetahuan dari pakar. Fakta dan pengetahuan yang telah didapatkan akan diterjemahkan knowledge engineer menjadi basis pengetahuan yang tersimpan dalam sistem pakar yang telah dibuat. Fakta tersebut ditampilkan dalam bentuk tabel gejala dan bobot gejala. Masing-masing gejala direpresentasikan dengan kode seperti digambarkan pada tabel 2 .

Tabel 2. Daftar Nilai CF Gejala Tuberkulosis

\begin{tabular}{|c|c|c|}
\hline $\begin{array}{c}\text { Kode } \\
\text { Gejala } \\
\end{array}$ & Nama Gejala & $\begin{array}{c}\text { Nilai } \\
\text { CF }\end{array}$ \\
\hline G01 & $\begin{array}{l}\text { Batuk terus-menerus dan berdahak } \\
\text { selama tiga minggu/lebih }\end{array}$ & 0.8 \\
\hline G02 & Dahak bercampur darah/batuk darah & 0.6 \\
\hline G03 & Demam yang berlangsung lama & 0.6 \\
\hline G04 & Sesak nafas dan nyeri dada & 0.6 \\
\hline G05 & Penurunan nafsu makan & 0.8 \\
\hline G06 & Penurunan berat badan & 0.8 \\
\hline G07 & Rasa kurang enak badan/malaise, lemah & 0.8 \\
\hline G08 & $\begin{array}{l}\text { Berkeringat di malam hari walaupun } \\
\text { tidak melakukan apa-apa }\end{array}$ & 0.6 \\
\hline G01a & $\begin{array}{l}\text { Batuk terus-menerus dan berdahak } \\
\text { selama tiga minggu/lebih }\end{array}$ & 0.4 \\
\hline G01b & $\begin{array}{l}\text { Batuk terus-menerus dan berdahak } \\
\text { selama tiga minggu/lebih }\end{array}$ & 0.4 \\
\hline G01c & $\begin{array}{l}\text { Batuk terus-menerus dan berdahak } \\
\text { selama tiga minggu/lebih }\end{array}$ & -0.6 \\
\hline G03a & Demam yang berlangsung lama & 0.4 \\
\hline G03b & Demam yang berlangsung lama & 0.6 \\
\hline G03c & Demam yang berlangsung lama & -0.4 \\
\hline G05a & Penurunan nafsu makan & 0.6 \\
\hline G05b & Penurunan nafsu makan & 0.4 \\
\hline G05c & Penurunan nafsu makan & 0.6 \\
\hline G06a & Penurunan berat badan & 0.6 \\
\hline G06b & Penurunan berat badan & 0.4 \\
\hline G06c & Penurunan berat badan & 0.8 \\
\hline G07a & Rasa kurang enak badan/malaise, lemah & 1.0 \\
\hline G07b & Rasa kurang enak badan/malaise, lemah & 1.0 \\
\hline G07c & Rasa kurang enak badan/malaise, lemah & 1.0 \\
\hline G08a & $\begin{array}{l}\text { Berkeringat di malam hari walaupun } \\
\text { tidak melakukan apa-apa }\end{array}$ & -0.4 \\
\hline G08b & $\begin{array}{l}\text { Berkeringat di malam hari walaupun } \\
\text { tidak melakukan apa-apa }\end{array}$ & -0.4 \\
\hline G08c & $\begin{array}{l}\text { Berkeringat di malam hari walaupun } \\
\text { tidak melakukan apa-apa }\end{array}$ & 0.4 \\
\hline G09 & $\begin{array}{l}\text { Munculnya benjolan-benjolan yang } \\
\text { terjadi pada bagian yang mengalami } \\
\text { gangguan kelenjar seperti leher, sela } \\
\text { paha, serta ketiak. }\end{array}$ & 1.0 \\
\hline G10 & $\begin{array}{l}\text { Ada tanda-tanda radang di daerah } \\
\text { sekitar benjolan kelenjar }\end{array}$ & 0.8 \\
\hline G11 & Benjolan kelenjar mudah digerakkan & 0.8 \\
\hline G12 & Benjolan kelenjar timbul terasa kenyal & 0.8 \\
\hline G13 & $\begin{array}{l}\text { Membesarnya benjolan kelenjar yang } \\
\text { mengakibatkan hari demi hari } \\
\text { kondisinya semakin memburuk dan } \\
\text { merusak tubuh. }\end{array}$ & 1.0 \\
\hline G14 & $\begin{array}{l}\text { Benjolan kelenjar pecah, mengeluarkan } \\
\text { cairan seperti nanah yang kotor. }\end{array}$ & 0.8 \\
\hline G15 & $\begin{array}{l}\text { Terdapat luka pada jaringan kulit atau } \\
\text { kulit yang disebabkan pecahnya } \\
\text { benjolan kelenjar getah bening }\end{array}$ & 1.0 \\
\hline G16 & Timbulnya benjolan di payudara. & 1.0 \\
\hline G17 & Rasa nyeri di bagian payudara. & 0.8 \\
\hline G18 & $\begin{array}{l}\text { Adanya tanda radang di sekitar benjolan } \\
\text { yang timbul di payudara. }\end{array}$ & 0.8 \\
\hline G19 & $\begin{array}{l}\text { Rasa nyeri/sakit pada bagian punggung } \\
\text { atau mengalami kekakuan punggung. }\end{array}$ & 1.0 \\
\hline G20 & $\begin{array}{l}\text { Penderita enggan menggerakkan } \\
\text { punggungnya. }\end{array}$ & 1.0 \\
\hline G21 & $\begin{array}{l}\text { Penderita menolak untuk membungkuk } \\
\text { atau mengangkat barang dari lantai, bila } \\
\text { diminta penderita akan menekuk } \\
\text { lututunya agar punggung tetap lurus. }\end{array}$ & 1.0 \\
\hline G22 & $\begin{array}{l}\text { Rasa nyeri/sakit pada punggung } \\
\text { berkurang bila penderita beristirahat. }\end{array}$ & 1.0 \\
\hline G23 & $\begin{array}{l}\text { Timbulnya benjolan di bagian } \\
\text { punggung/tulang belakang }\end{array}$ & 0.6 \\
\hline
\end{tabular}


Setiap jenis penyakit Tuberkulosis direpresentasikan dengan kode seperti yang tercantum pada tabel 3 berikut:

Tabel 3. Daftar Jenis Penyakit Tuberkulosis.

\begin{tabular}{|l|l|}
\hline $\begin{array}{c}\text { Kode } \\
\text { Penyakit }\end{array}$ & \multicolumn{1}{c|}{ Nama Penyakit } \\
\hline P01 & Tuberkulosis Paru \\
\hline P02 & Tuberkulosis Kelenjar Getah Bening \\
\hline P03 & Tuberkulosis Payudara \\
\hline P04 & Tuberkulosis Tulang Belakang \\
\hline
\end{tabular}

\section{e. Implementasi Sistem}

Sistem Pakar diagnosa penyakit Tuberkulosis memiliki beberapa bagian yang selalu tampil pada setiap halaman web, yaitu bagian header, menu samping, dan footer.

1. Halaman Utama Website

Halaman utama website memiliki menu utama yang terletak di bagian kiri yang terdiri dari menu Login, menu Bantuan, dan menu About Me. Tampilan Halaman Utama Website dapat dilihat pada gambar 2 .

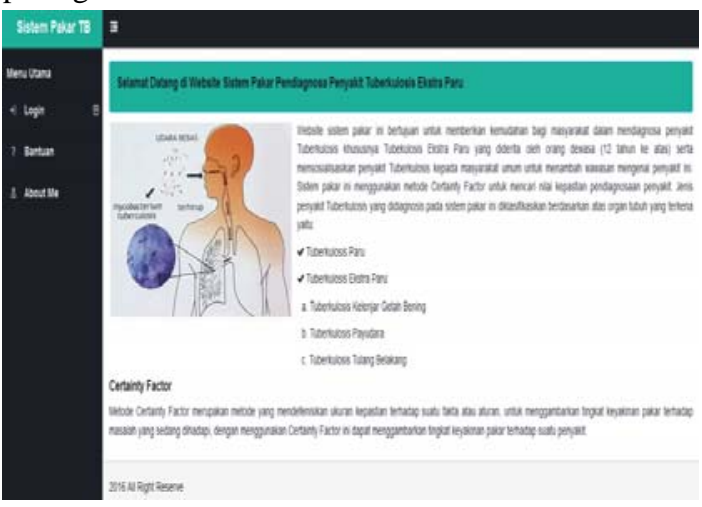

Gambar 2. Halaman Utama atau Home

\section{Menu Login User}

Menu Login User digunakan untuk menampilkan halaman login user. Halaman login user berfungsi sebagai pintu masuk yang digunakan user untuk dapat masuk ke dalam akun user. Setiap user yang ingin melakukan konsultasi pada sistem ini diharuskan untuk memiliki akun terlebih dahulu agar data dan privasi user dapat terjaga.

3. Halaman Dashboard User

Halaman utama user atau Dashboard adalah halaman utama/halaman beranda yang pertama kali tampil ketika user berhasil login ke dalam akun user. User harus melakukan login dulu sebelum halaman utama user tampil. Halaman utama user berisi beberapa widget yaitu kuisioner resiko, konsultasi, informasi penyakit \& faktor resiko, dan rekam medis yang dapat digunakan user secara langsung selain menggunakan menu utama. Tampilan Halaman Utama User dapat dilihat pada gambar 3.

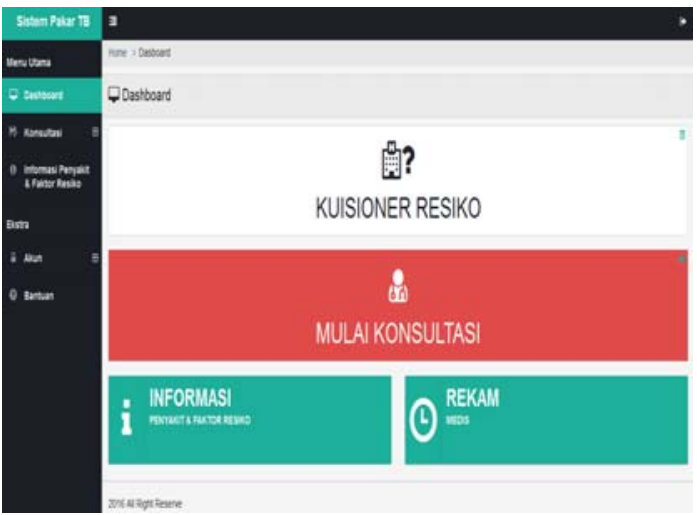

Gambar 3. Halaman Dashbord User

User dapat menggunakan widget Kuisioner Resiko yang terdapat pada halaman beranda user untuk mengisi kuisioner. Kuisioner Resiko berfungsi sebagai pemberi informasi seberapa besar resiko user untuk terserang penyakit Tuberkulosis. Kuisioner Resiko merupakan kuisioner yang berisi pertanyaan mengenai beberapa faktor resiko kejadian Tuberkulosis. Pertanyaan yang diajukan kepada user terdiri dari 13 pertanyaan faktor resiko Tuberkulosis dan disediakan dua pilihan jawaban “ya”, “mungkin”, dan "tidak”. Tampilan Halaman Kuisioner Resiko dapat dilihat pada gambar 4.

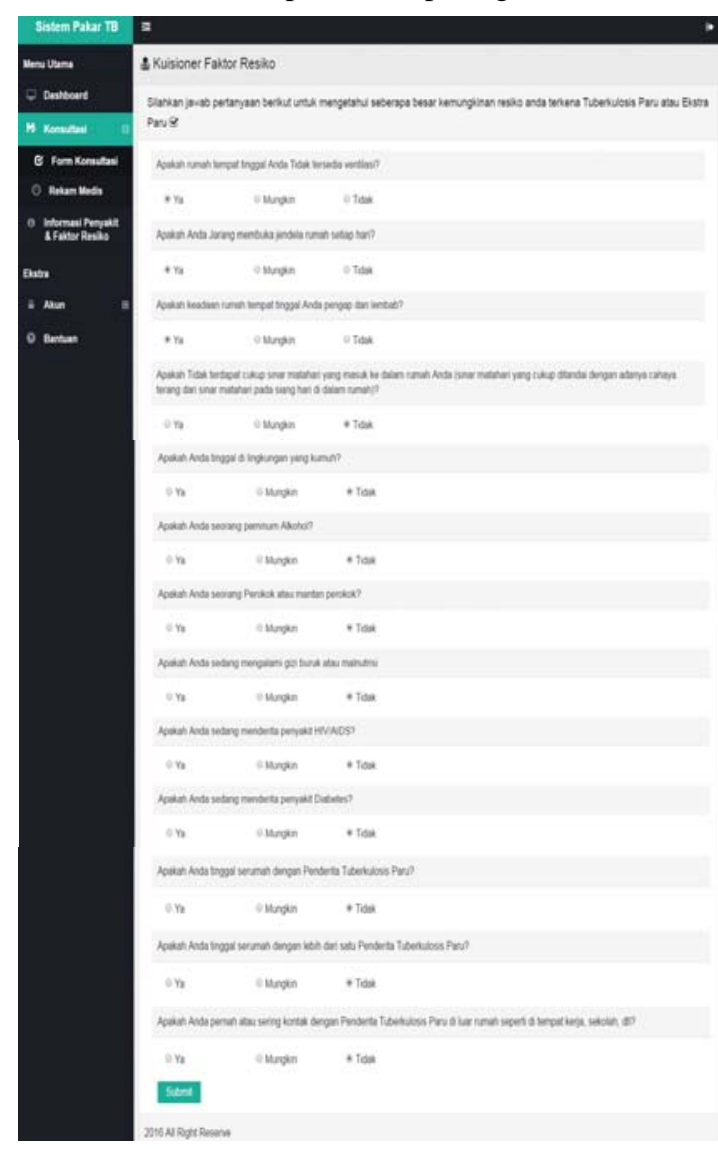

Gambar 4. Halaman Kuisioner Resiko

User harus menjawab semua pertanyaan Kuisioner Resiko untuk mendapatkan hasil resiko Tuberkulosis yang dimiliki. Setelah user mengisi 
kuisioner resiko kejadian Tuberkulosis maka halaman hasil Kuisioner Resiko akan tampil. Halaman hasil Kuisioner Resiko berisi hasil apakah user memiliki kemungkinan resiko untuk terserang penyakit Tuberkulosis atau tidak, daftar faktor resiko yang dimiliki user berdasarkan jawaban yang telah dipilih user untuk setiap pertanyaan resiko. Tampilan Halaman Hasil Kuisioner Resiko dapat dilihat pada gambar 5 .

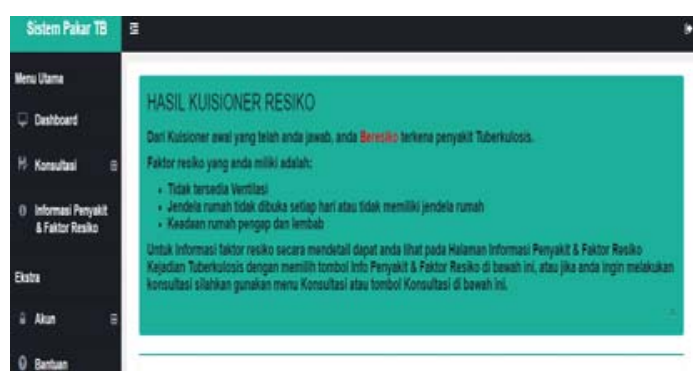

Gambar 5. Halaman Hasil Kuisioner Resiko

a. Menu Konsultasi

Menu konsultasi adalah menu yang menampilkan halaman Konsultasi. User dapat memulai konsultasi pada halaman ini dengan memilih gejala-gejala yang ada sesuai yang dialami oleh user. Inputan gejala user akan menjadi masukan sistem pakar untuk diproses. Sistem akan mengecek apakah inputan gejala-gejala dari user terdapat rule yang sesuai atau tidak. Jika inputan gejala user sesuai dengan rule penyakit yang ada maka akan dilakukan proses perhitungan dengan menggunakan metode Certainty Factor dan menghasilkan hasil diagnosa kemungkinan penyakit TB Paru dan Ekstra Paru beserta persentasi nilai kemungkinannya. Jika tidak sesuai dengan rule penyakit yang ada maka sistem akan memberikan hasil output bahwa user tidak terdiagnosa terkena penyakit TB. Di bawah ini langkah-langkah yang dapat dilakukan user untuk melakukan konsultasi:

1) User memilih gejala penyakit Tuberkulosis yang dialami. Tampilan Form Konsultasi dapat dilihat pada gambar 6 .

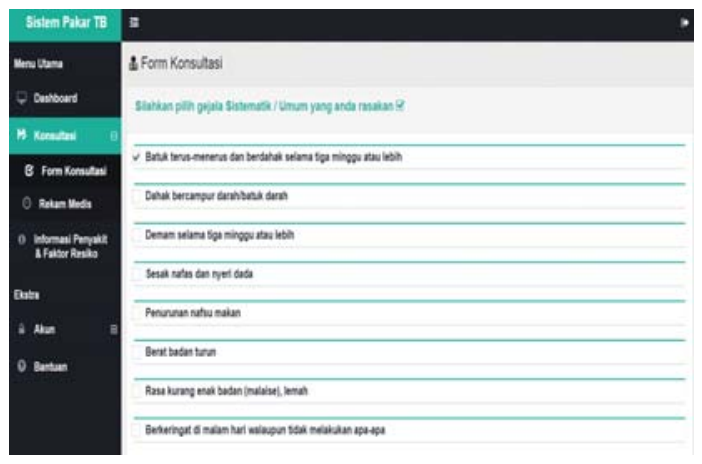

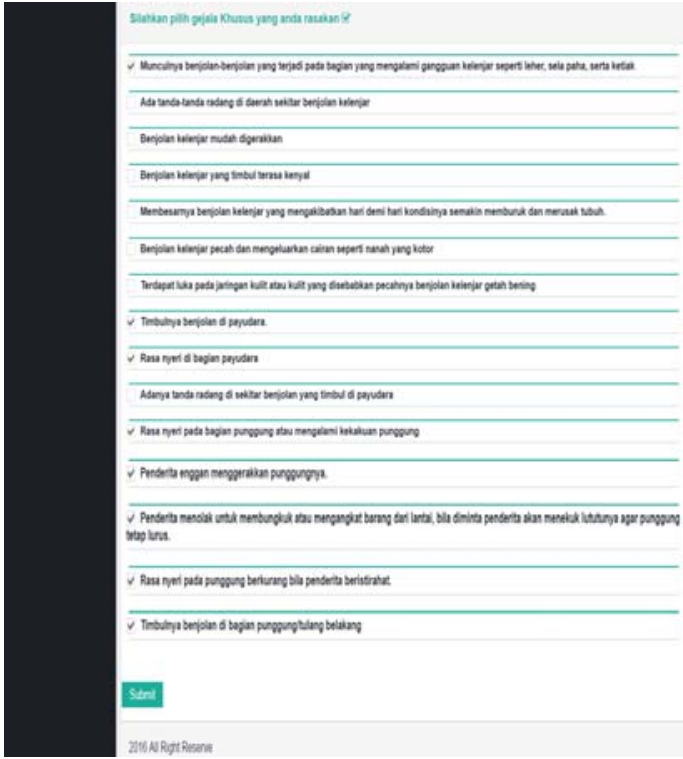

Gambar 6. Form Konsultasi

2) User menekan tombol submit setelah memilih gejala yang dialami kemudian sistem akan menampilkan hasil diagnosa kemungkinan penyakit pada halaman detail diagnosa. Tampilan Detail Diagnosa dapat dilihat pada gambar 7.

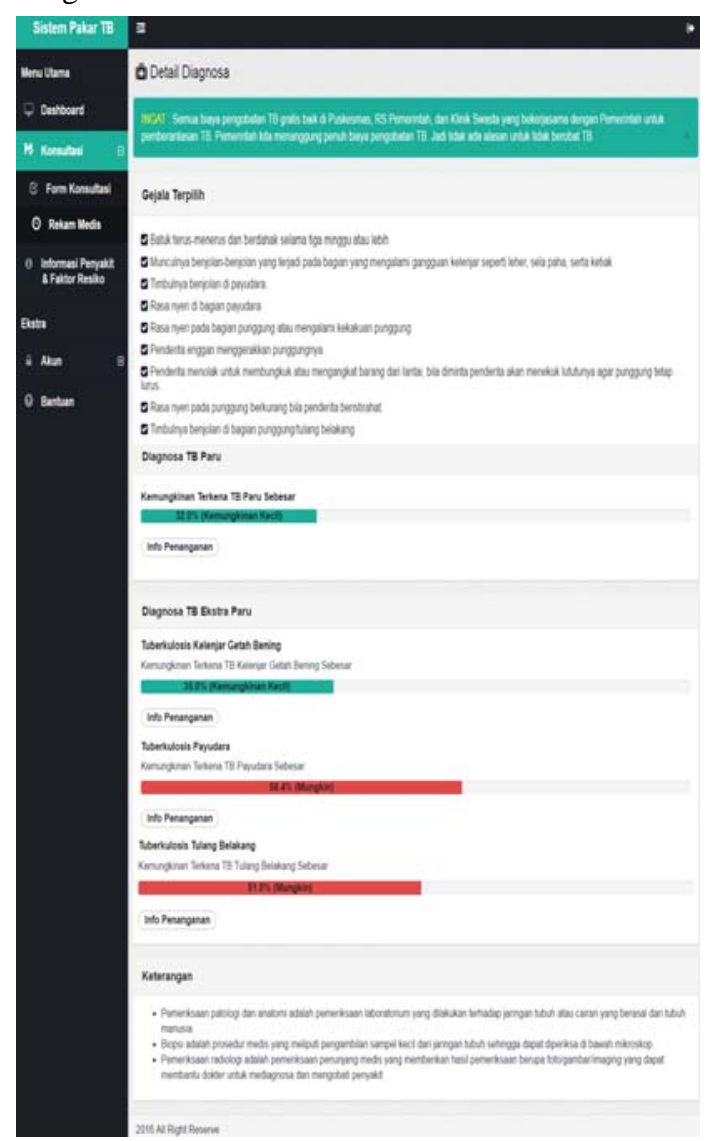

Gambar 7. Halaman Detail Diagnosa

User dapat melihat gejala yang telah diinputkan dan kemungkinan penyakit TB yang terkena beserta 
nilai kemungkinan dan info penanganannya pada halaman detail diagnosa. User dapat melihat info penanganan penyakit dengan menekan tombol "info penanganan” pada halaman detail diagnosa. Di bawah ini gambar info penanganan salah satu diagnosa penyakit yaitu Tuberkulosis TB Kelenjar Getah Bening. Tampilan Informasi Penanganan dapat dilihat pada gambar 8 .
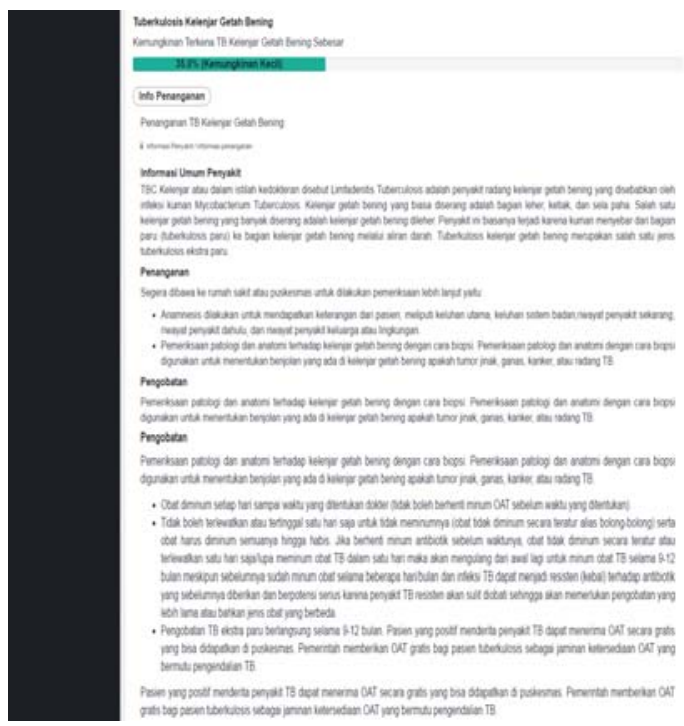

Gambar 8. Halaman Informasi Penanganan TB Kelenjar Getah Bening

\section{KESIMPULAN}

Berdasarkan hasil penelitian mengenai sistem pakar pendiagnosa penyakit Tuberkulosis Paru dan Ekstra Paru dengan menggunakan metode Certainty Factor, dapat diambil kesimpulan:

1. Telah dihasilkan sebuah sistem pakar untuk diagnosa awal penyakit Tuberkulosis Paru dan Ekstra Paru pada orang dewasa (usia lebih dari 12 tahun) berbasis web yang dibangun dengan menggunakan metode inferensi forward chaining dan teori Certainty Factor (CF) serta menggunakan bahasa pemrograman PHP dan database MySQL.

2. Sistem pakar ini bekerja berdasarkan gejala yang dipilih user kemudian diproses oleh sistem sehingga menghasilkan output yaitu nama penyakit, presentase keyakinan diagnosa dan informasi penanganan penyakit.

3. Sistem Pakar Pendiagnosa Penyakit Tuberkulosis mempunyai tingkat akurasi diagnosa penyakit sebesar $85 \%$.

\section{DAFTAR PUSTAKA}

[1]. Alfaris, S. 2014. "Sistem Pakar untuk Mendiagnosa Penyakit Polip Nasi (Polip Hidung) Menggunakan Metode Certainty Factor”. Pelita Informatika Budi Darma, Vol. VII Nomor 2. Agustus 2014.

[2]. Arhami, M. 2005. Konsep Dasar Sistem Pakar. Yogyakarta: Andi.
[2] Depkes RI, Ditjen PP dan PL. 2008. Pedoman Nasional Penanggulangan Tuberkulosis dan Standar Internasional Untuk Pelayanan Tuberkulosis. Departemen Kesehatan Republik Indonesia.

[3] Hiswani 2008. “Tuberkulosis Merupakan Penyakit Infeksi yang Masih Menjadi Masalah Kesehatan Masyarakat”. Skripsi. Universitas Sumatera Utara.

[4] Kadir, Abdul. 2008. Dasar Pemrograman Web Dinamis Menggunakan PHP - Edisi Revisi, ANDI, Yogyakarta.

[5] Kementrian Kesehatan RI. 2011. Pedoman Nasional Penanggulangan Tuberkulosis. Jakarta: Kementrian Kesehatan RI.

[6] Kementrian Kesehatan RI. 2014. Pedoman Nasional Pengendalian Tuberkulosis. Jakarta: Kementrian Kesehatan RI. 2014.

[7] Kusrini. 2008. Aplikasi Sistem Pakar. Yogyakarta: Andi Offset.

[8] Madcoms. 2011. Adobe Dreamweaver CS5 dengan Pemrograman PHP \& MySQL. Yogyakarta : Penerbit Andi.

[9] Mahdiana, R. 2010. Panduan Lengkap Kesehatan Mengenal, Mencegah dan Mengobati Penularan Penyakit dari Infeksi. Yogyakarta: Citra Pustaka.

[10] Martin, J. Dan Oxman, S. 1988. Building Expert Systems a Tutorial. New Jersey: Prentice Hall.

[11] Misnadiarly. 2006. Diabetes Melitus Gangren, Ulcer, Infeksi, Mengenali gejala, Menanggulangi, dan Mencegah komplikasi. Jakarta: Pustaka Obor Populer.

[12] Sari, W.W. 2013. "Perancangan Sistem Pakar untuk Mengetahui Infertilitas Pada Perempuan Menggunakan Metode Certainty Factor”. Pelita Informatika Budi Darma, Vol. V Nomor 1. November 2013.

[13] Sutejo, T., Mulyanto, E., dan Suhartono, V. 2011. Kecerdasan Buatan. Yogyakarta: Andi.

[14] Turban, 2005. Decision Support System, Intelligent System. Jilid II. Edisi 7. Yogyakarta. Percetakan Andi Offset. Penerbit Andi.

[15] WHO. 2013. WHO Report 2013-Global Tuberculosis

Control. www.who.int/tb/data. diunduh pada tanggal 05 April 2016. 